\title{
The human C-type lectin 18 is a potential biomarker in patients with chronic hepatitis $B$ virus infection
}

Tsung-Yu Tsai ${ }^{1,2}$, Cheng-Yuan Peng ${ }^{2,3}$, Hwai-I Yang ${ }^{4}$, Ya-Lang Huang ${ }^{4}$, Mi-Hua Tao ${ }^{5}$, Shin-Sheng Yuan ${ }^{6}$, Hsueh-Chou Lai ${ }^{2}$ and Shie-Liang Hsieh ${ }^{4,7,8^{*}}$

\begin{abstract}
Background: Hepatitis B virus (HBV) infection is a common disease worldwide and is known to cause liver disease. C-type lectin 18 (CLEC18) is a novel secretory lectin highly expressed in human hepatocytes. Because the liver is the major target of HBV infection, we investigated whether the expression of CLEC18 can be used as a biomarker for HBV infection.

Methods: The expression level of CLEC18 in human liver chimeric mice with/without HBV infection was measured by quantitative real time polymerase chain reaction (qPCR) assay. Baseline plasma CLEC18 levels in 271 treatmentnaive patients with chronic hepatitis B (CHB) undergoing nucleos(t)ide analogue (NUC) therapy and 35 healthy donors were measured by enzyme-linked immunosorbent assay, and the relationships to other clinical data were analyzed.

Results: The expression of CLEC18 was down-regulated in the human liver chimeric mice after HBV infection. Plasma CLEC18 levels were lower in the patients with CHB compared to the healthy donors and positively correlated with HBV DNA and HBsAg levels $(P<0.05)$. Multivariate Cox proportional hazard regression analysis identified a baseline plasma CLEC18 level of 320-2000 pg/mL to be an independent predictor of HBeAg loss (hazard ratio (HR): 2.077, $P=0.0318$ ), seroconversion (HR: 2.041, $P=0.0445$ ) and virological response (HR: 1.850, $P=0.0184$ ) in $101 \mathrm{HBeAg}$-positive patients with CHB undergoing NUC therapy.

Conclusions: Plasma CLEC18 levels were correlated with the stage of HBV infection and could predict HBeAg loss and seroconversion in the patients with CHB undergoing NUC therapy.
\end{abstract}

Keywords: Hepatitis B virus, C-type lectin 18, HBeAg seroconversion

\section{Background}

Hepatitis B virus (HBV) infection is a global health problem. Current treatment options for hepatitis B e antigen ( $\mathrm{HBeAg}$ )-positive $\mathrm{HBV}$-infected patients include interferon therapy and nucleos(t)ide analogues (NUCs). $\mathrm{HBeAg}$ loss and seroconversion are defined as an intermediate therapeutic endpoint in $\mathrm{HBeAg}$-positive patients $[1,2]$. Evaluating the treatment outcome, the status of liver fibrosis is important for patients with chronic hepatitis B (CHB). Clinically, a decline in HBV DNA levels

\footnotetext{
* Correspondence: edmond158162@gmail.com

${ }^{4}$ Genomics Research Center, Academia Sinica, 128, Academia Road, Sec. 2 Nankang District, Taipei 115, Taiwan

${ }^{7}$ Institute of Clinical Medicine, National Yang-Ming University, Taipei, Taiwan Full list of author information is available at the end of the article
}

during treatment and high serum alanine aminotransferase (ALT) level can predict $\mathrm{HBeAg}$ loss and $\mathrm{HBeAg}$ seroconversion [3]. A liver biopsy is the gold standard method to assess the stage of liver fibrosis, although it has the disadvantage of a high complication rate. Noninvasive methods using biomarkers such as hepatitis B surface antigen (HBsAg), serum ALT levels [4], and scoring systems such as fibrosis-4 (FIB-4) and aspartate aminotransferase (AST) to platelet ratio index (APRI) have also been proposed $[5,6]$. However, these methods have limitations as independent disease markers [7, 8]. In addition, other immune markers such as tumor necrosis factor-alpha (TNF- $\alpha$ ), programmed cell death protein-1 (PD-1) [9] and serum markers such as apolipoprotein and haptoglobulin are not specific for HBV disease and

(c) The Author(s). 2018 Open Access This article is distributed under the terms of the Creative Commons Attribution 4.0 International License (http://creativecommons.org/licenses/by/4.0/), which permits unrestricted use, distribution, and 
can easily be influenced by other diseases [8]. Biomarkers to assess the treatment outcome of HBV infection and liver fibrosis are still under development.

C-type lectin 18 (CLEC18) is a novel secretory C-type lectin, and we previously showed that CLEC18 is highly expressed in the liver. It is localized in the endoplasmic reticulum, Golgi apparatus, and endosomes, and it can be detected in human plasma by enzyme-linked immunosorbent assay (ELISA). CLEC18 is secreted into the culture supernatant of innate immune cells such as monocytes, dendritic cells and macrophages, which suggests that it is related to the function of the innate immune system [10].

HBV can weaken the host immune response without inducing a pattern recognition receptor (PRR)-mediated cytokine response $[11,12]$. The mechanisms by which HBV attenuates Toll-like receptor (TLR)-mediated cytokine responses have been investigated [13], however an association between CLEC18 and HBV infection has yet to be elucidated.

The liver is the major target of HBV infection, and CLEC18 is highly expressed in the liver. Therefore, we hypothesized that the expression of CLEC18 would be influenced by HBV infection. The aim of this study was to investigate the expression of CLEC18 in the liver and its potential role as a biomarker for $\mathrm{HBV}$ infection.

\section{Methods}

\section{Infection of human liver chimeric mice with HBV}

Human liver chimeric mice were generated from Fah -/-/Rag2-/-/Il2rg-/- mice (FRG mice) with transplanted human hepatocytes (kindly provided by Dr. Mi-Hua Tao) [14-16]. Each human liver chimeric mouse was infected with $\mathrm{HBV}$, produced by HBV transgenic mice using the hydrodynamic vein injection method as described previously [14]. In brief, 6-week-old FRG mice were intrasplenically transplanted with human hepatocytes (BD Biosciences, USA). HBV obtained from ICR/ HBV transgenic mice was hydrodynamically injected into the FRG mice after 3-4 months of transplantation, as previously described [17]. The mice were then sacrificed at 10 and 26 weeks after HBV infection, and liver samples were collected for analysis.

\section{CLEC18 detection in the human liver chimeric mice with/ without HBV infection}

Total ribonucleic acid (RNA) was extracted from liver tissues using Trizol according to the manufacturer's instructions (Invitrogen, USA). The RNA was subjected to reverse transcription using a RevertAid ${ }^{\mathrm{Ts}}$ First Strand complementary DNA (cDNA) Synthesis Kit (Fermentas), and was then used as the template for polymerase chain reaction (PCR) amplification. CLEC18 cDNA levels in the liver tissue were quantified by real-time PCR using hybridization probes (Roche Life Science, $\mathrm{CH}$ ) with a thermocycler (LightCycler480 4 II, Roche, $\mathrm{CH}$ ) as previously described [13].

\section{Patients}

We enrolled 271 treatment-naïve patients with $\mathrm{CHB}$ (101 positive and 170 negative for HBeAg) who received NUC treatment with indications according to the guidelines of the Asian Pacific Association for the Study of the Liver (APASL) at the Hepatology Clinic of China Medical University Hospital in Taichung, Taiwan from August 2005 to August 2016 [2]. The inclusion criteria were age $\geq 20$ years and a history of HBsAg carriage for more than 6 months. The exclusion criteria were coinfection caused by other etiologies such as hepatitis $\mathrm{C}$ virus, hepatitis $\mathrm{D}$ virus, or human immunodeficiency virus; decompensated liver disease; other forms of liver disease; hepatocellular carcinoma at baseline; coexisting severe medical diseases or cancer; and the concurrent use of immunomodulatory drugs or corticosteroids. Among the $101 \mathrm{HBeAg-positive} \mathrm{patients,} 80$ received entecavir, 17 received tenofovir, three received telbivudine, and one received lamivudine. Of these patients, 56 achieved HBeAg loss and 36 achieved HBeAg seroconversion. All of these patients received NUC therapy until the end of the follow-up period of this study, and none experienced viral resistance. Plasma was stored in $-80^{\circ}$ $\mathrm{C}$ refrigerators. We also enrolled 35 healthy donors who volunteered for blood donation (17 men and 18 women, 14 aged $>40$ years and 21 aged $<40$ years). Healthy donors were defined as those who did not have any chronic diseases or cancer and had normal annual health examination reports, including ALT.

\section{Laboratory examinations}

Baseline plasma CLEC18 levels were measured retrospectively using our inhouse ELISA (being licensed to Biolegend) and ELISA from CUSABIO Life Science. We tested both ELISA kits with recombinant proteins and healthy donor sera. Both ELISA kits had a lower limit of detection of $0.078 \mathrm{ng} / \mathrm{mL}$ and correlated with each other well. Platelets, prothrombin time (PT), and serum levels of albumin, total bilirubin, creatinine, alpha-fetoprotein (AFP), ALT and serum HBV DNA were measured at baseline. HBeAg and anti-HBe antibodies (Architect i2000 assay; Abbott Diagnostics, Abbott Park, IL, USA) were detected before treatment in order to categorize the patients as being $\mathrm{HBeAg}$ positive or negative. $\mathrm{HBeAg}$ and anti-HBe antibodies were detected at baseline and every 3 months during treatment in the HBeAg-positive group. HBsAg levels were quantified retrospectively in the patients enrolled before September 2009 and prospectively in those enrolled thereafter using Abbott Architect HBsAg QT assays (dynamic range, $0.05-250 \mathrm{IU} / \mathrm{mL}$ ) at baseline 
and annually thereafter. Serum HBV DNA levels were measured at baseline, 3, 6, and 12 months; and then every 6 months thereafter.. HBV genotyping was performed as previously described [18]. Liver fibrosis (F) was staged according to the METAVIR system [19]. Cirrhosis was defined by one of the following: 1) presence of cirrhosis-related complications such as ascites and esophageal or gastric varices; 2) ultrasonographic evidence of a nodular surface and coarse echotexture of the liver with ascites and/or splenomegaly; and 3) histology. Fatty liver was defined on the basis of repeated ultrasonographic findings with increased echogenicity in the liver. Liver biopsies in these patients were performed before NUC therapy.

\section{Definition of cutoff values}

We stratified the patients into three subgroups according to the values close to the cutoff values of baseline plasma CLEC18 (319.52 and $2015.08 \mathrm{pg} / \mathrm{mL}$, risk estimate: 0.297) and HBsAg levels (2889.3-12,022.2 IU/mL, risk estimate: 0.366) which were associated with the highest rates of $\mathrm{HBeAg}$ loss in the patients with $\mathrm{CHB}$ receiving NUC therapy using classification and regression tree (CART) analysis (see Additional File 1). We defined the cutoff for age (40 years) and HBV DNA (8.3 $\log _{10}$ $\mathrm{IU} / \mathrm{mL}$ ) as the median of the 101 patients, and the cutoff for ALT ( $5 \times$ upper limit of normal (ULN)) according to a previous study [20]. The cutoff values for total bilirubin, PT, platelet, and AFP were based on normal values, and those for APRI and FIB-4 were based on previous reports $[8,9,21]$.

\section{Therapeutic endpoints}

$\mathrm{HBeAg}$ loss was defined as the absence of serum HBeAg during NUC treatment, and $\mathrm{HBeAg}$ seroconversion was defined as $\mathrm{HBeAg}$ loss with the presence of anti-HBe antibodies. Virological response was defined as undetectable serum HBV DNA.

\section{Statistical analysis}

Continuous variables were compared between two groups using the Student's t-test $(\mathrm{T})$, labeled as “ $\mathrm{T}$ ” in Table 1, and presented as the mean \pm standard deviation (SD). Categorical variables were analyzed using the chi-squared test, labeled as "C" in Table 1 . Linear regression analysis was used to identify factors associated with CLEC18 expression. Cox proportional hazard regression analysis was used to identify factors associated with HBeAg loss, seroconversion, and virological response. Logistic regression analysis was used to identify factors associated with liver pathological fibrosis stage. Kaplan-Meier analysis and the log-rank test were used to compare the cumulative incidence rates of $\mathrm{HBeAg}$ loss and seroconversion in subgroups of patients with
CHB. SAS version 9.4 (SAS Institute, Inc., Cary, NC, USA) and SPSS (IBM Corp. Released 2013, IBM SPSS Statistics for Windows, Version 22.0. Armonk, NY, USA) were used for statistical analyses. A two-sided $P$ value of $<0.05$ was considered to be statistically significant.

\section{Results}

Down-regulation of the expression of CLEC18 in the liver The relative mRNA expression levels of human CLEC18 were dramatically down-regulated in the liver tissues of HBV-infected human liver chimeric mice at 10 and 26 weeks after infection compared to the non-infected controls. Mouse CLEC18 was not detected, indicating that the liver tissue collected was only human (Fig. 1). This finding suggested that HBV down-regulated the expression of CLEC18 in human hepatocytes.

\section{Baseline patient characteristics}

The baseline patient characteristics are presented in Table 1. In brief, the HBeAg-positive patients were significantly younger and had lower prevalence rates of genotype $\mathrm{B}$ infection and cirrhosis, a higher platelet count, and higher levels of ALT, HBV DNA, and HBsAg than the HBeAg-negative patients.

\section{Decreased plasma CLEC18 levels in the patients with CHB} In order to understand the role of CLEC18 in different stages of $\mathrm{CHB}$, we divided the patients with $\mathrm{CHB}$ into four groups according to the presence of $\mathrm{HBeAg}$ and HBV DNA levels. The mean plasma CLEC18 levels were $3106,663,281,264$, and $113 \mathrm{pg} / \mathrm{mL}$ in the healthy donors $(n=35)$, treatment-naïve $\mathrm{HBeAg}$-positive $\mathrm{CHB}$ patients with $\mathrm{HBV}$ DNA $>2.0 \times 10^{7} \mathrm{IU} / \mathrm{mL} \quad(n=101)$, HBeAg-negative $\mathrm{CHB}$ patients with $\mathrm{HBV}$ DNA $>2.0 \times$ $10^{7} \mathrm{IU} / \mathrm{mL}(n=65)$, DNA $2000-2.0 \times 10^{7} \mathrm{IU} / \mathrm{mL}(n=64)$, and DNA $<2000 \mathrm{IU} / \mathrm{mL}(n=41)$, respectively. The plasma CLEC18 level was significantly lower in each HBV-infected group compared to the healthy donors and in the $\mathrm{HBeAg}$-negative group compared to $\mathrm{HBeAg-positive}$ group $(P<0.05-0.001)$ (Table 2$)$. There were no significant changes in plasma CLEC18 levels with different viral loads in the HBeAg-negative patients.

\section{Factors associated with plasma CLEC18 levels in the patients with $\mathrm{CHB}$}

We used univariate and multivariate linear regression analyses to identify factors associated with plasma CLEC18 levels in the patients with CHB (Table 3). Univariate analysis revealed that age was negatively associated with plasma CLEC18 levels, and that HBeAg positivity, HBsAg, HBV DNA, and ALT levels were positively associated with plasma CLEC18 levels. Multivariate analysis identified age to be a marginal independent factor associated with plasma CLEC18 levels. 
Table 1 Baseline patient characteristics

\begin{tabular}{|c|c|c|c|c|}
\hline $\begin{array}{l}\text { Variables } \\
\text { Mean } \pm \text { SD or N (\%) }\end{array}$ & $\begin{array}{l}\text { Total } \\
(n=271)\end{array}$ & $\begin{array}{l}\text { HBeAg-negative } \\
(n=170)\end{array}$ & $\begin{array}{l}\text { HBeAg-positive } \\
(n=101)\end{array}$ & P Value \\
\hline Age & $47.39 \pm 11.35$ & $51.57 \pm 10.45$ & $40.37 \pm 10.44$ & $<0.0001^{\top}$ \\
\hline Gender & & & & $0.6454^{c}$ \\
\hline Man & $187(69.0)$ & $119(70.0)$ & $68(67.33)$ & \\
\hline Woman & $84(31.0)$ & $51(30.0)$ & $33(32.67)$ & \\
\hline Genotype & & & & $0.0003^{c}$ \\
\hline B & $166(62.88)$ & $118(71.08)$ & $48(48.98)$ & \\
\hline C & 98 (37.12) & $48(28.92)$ & $50(51.02)$ & \\
\hline $\mathrm{HBsAg}: \log _{10} \mathrm{IU} / \mathrm{mL}$ & $3.34 \pm 0.84$ & $3.04 \pm 0.89$ & $3.85 \pm 0.66$ & $<0.0001^{\top}$ \\
\hline HBV DNA: $\log _{10} \mathrm{IU} / \mathrm{mL}$ & $6.89 \pm 2.16$ & $5.91 \pm 1.84$ & $8.56 \pm 0.93$ & $<0.0001^{\top}$ \\
\hline Cirrhosis & & & & $0.0028^{C}$ \\
\hline No & $182(67.16)$ & $103(60.59)$ & 79 (78.22) & \\
\hline Yes & $89(32.84)$ & $67(39.41)$ & $22(21.78)$ & \\
\hline Fatty liver & & & & $0.2510^{C}$ \\
\hline No & $133(49.08)$ & $88(51.76)$ & $45(44.55)$ & \\
\hline Yes & $138(50.92)$ & $82(48.42)$ & $56(55.45)$ & \\
\hline Albumin: g/dL & $4.07 \pm 0.51$ & $4.04 \pm 0.54$ & $4.10 \pm 0.48$ & $0.5446^{\top}$ \\
\hline ALT: IU/L & $281.5 \pm 411.2$ & $210.8 \pm 333.2$ & $400.5 \pm 472.3$ & $0.0002^{\top}$ \\
\hline Total bilirubin: mg/dL & $1.40 \pm 1.34$ & $1.32 \pm 0.95$ & $1.54 \pm 1.54$ & $0.7096^{\top}$ \\
\hline Platelet: $\times 10^{3} / \mu \mathrm{L}$ & $161.0 \pm 60.73$ & $149.4 \pm 65.8$ & $180.8 \pm 58.1$ & $0.0004^{\top}$ \\
\hline PT: seconds prolonged & $1.71 \pm 2.00$ & $1.69 \pm 1.73$ & $1.86 \pm 1.91$ & $0.3551^{\top}$ \\
\hline $\mathrm{Cr}: \mathrm{mg} / \mathrm{dL}$ & $0.88 \pm 0.49$ & $0.90 \pm 0.61$ & $0.86 \pm 0.40$ & $0.2857^{\top}$ \\
\hline AFP: $n g / m L$ & $25.31 \pm 75.62$ & $21.24 \pm 44.57$ & $32.17 \pm 89.88$ & $0.4094^{\top}$ \\
\hline Numbers of liver biopsy & 164 & 105 & 59 & \\
\hline METAVIR Activity grade & & & & $0.5302^{c}$ \\
\hline 0,1 & $97(59.15)$ & $64(60.95)$ & $33(55.93)$ & \\
\hline 2,3 & $67(40.85)$ & $41(39.05)$ & $26(44.07)$ & \\
\hline METAVIR Fibrosis stage & & & & $0.0949^{c}$ \\
\hline $0-2$ & $91(57.59)$ & $52(52.53)$ & $39(66.10)$ & \\
\hline 3,4 & $67(42.41)$ & $47(47.47)$ & $20(33.90)$ & \\
\hline
\end{tabular}

T Student's T-test, C Chi-squared test

Role of plasma CLEC18 in the prediction of HBeAg loss and seroconversion in the patients with $\mathrm{CHB}$ receiving NUC treatment

The overall NUC treatment duration was $59.51 \pm$ 3.21 months for the HBeAg-positive patients. The times to HBeAg loss and seroconversion were $37.69 \pm 2.86$ months and $45.61 \pm 3.26$ months, respectively. Among the 101 HBeAg-positive patients, 56 (55.44\%) patients experienced HBeAg loss and 36 (35.64\%) patients experienced HBeAg seroconversion during NUC treatment.

Univariate analysis identified that baseline ALT level $>5 \times$ ULN, AFP > $20 \mathrm{ng} / \mathrm{mL}$, HBsAg level of 2900-12,000 IU/ $\mathrm{mL}$, and plasma CLEC18 level of $320-2000 \mathrm{pg} / \mathrm{mL}$ were significantly associated with $\mathrm{HBeAg}$ loss (Table 4), and that baseline ALT level > 5x ULN, AFP > $20 \mathrm{ng} / \mathrm{mL}$, and plasma
CLEC18 level of 320-2000 pg/mL were significantly associated with $\mathrm{HBeAg}$ seroconversion (Table 5). Multivariate analysis identified that a baseline plasma CLEC18 level of 320-2000 pg/mL was an independent predictor of $\mathrm{HBeAg}$ loss (hazard ratio [HR]: 2.077, 95\% confidence interval $[\mathrm{CI}]: 1.066-4.046, P=0.0318)$ and seroconversion (HR: 2.041, 95\% CI: 1.018-4.092, $P=0.0445$ ) in the patients with $\mathrm{CHB}$ receiving NUC therapy. Baseline HBsAg level could significantly predict HBeAg loss (Table 4).

The cumulative incidence rates of $\mathrm{HBeAg}$ loss and seroconversion in the patients with $\mathrm{CHB}$ undergoing NUC therapy with a baseline plasma CLEC18 level of 320-2000 pg/mL were significantly higher than those in the other patients $(P<0.001$ and $P=0.002$, respectively) 


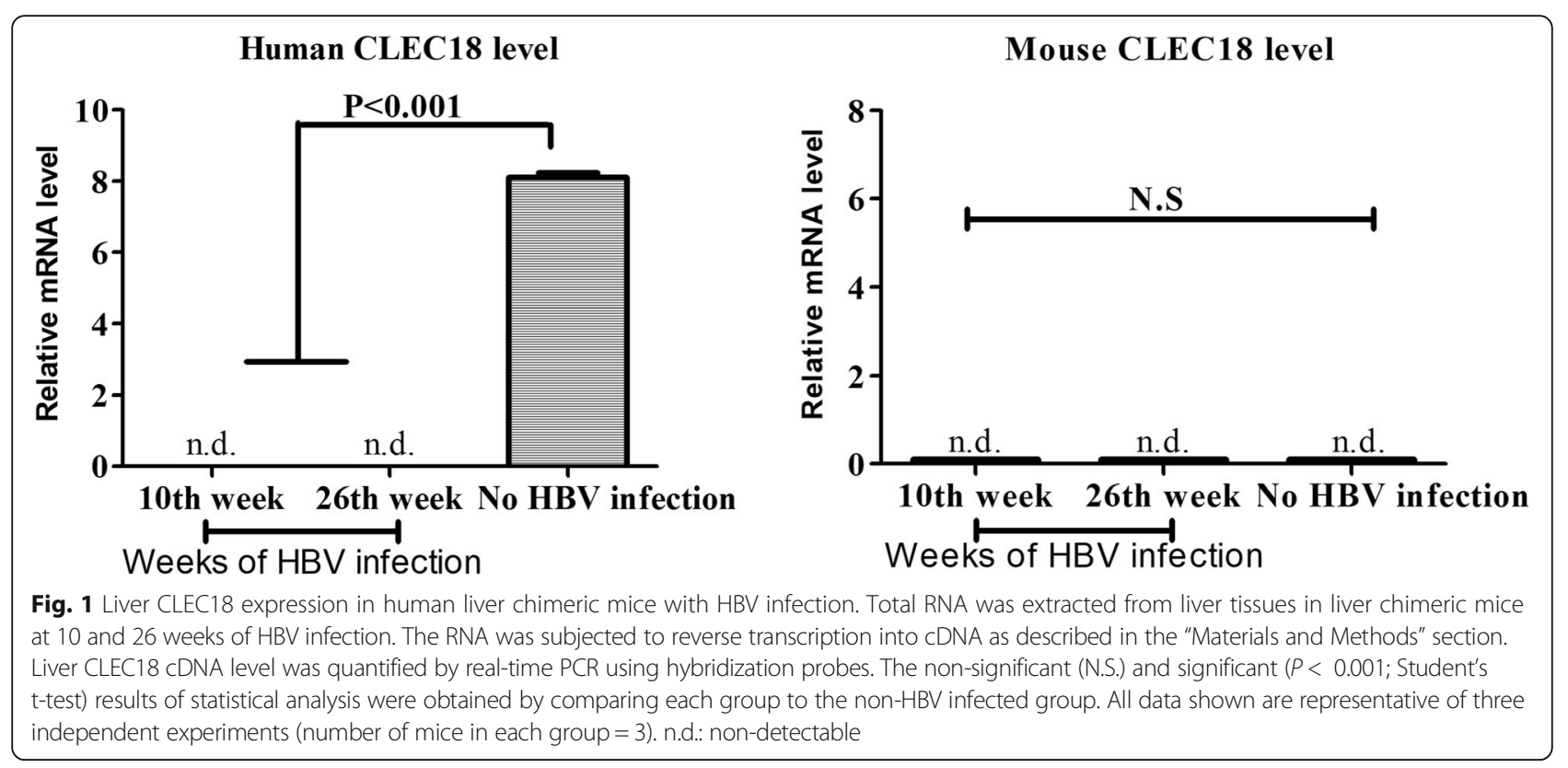

(Fig. 2a). The cumulative incidence of HBeAg loss but not $\mathrm{HBeAg}$ seroconversion in the patients with $\mathrm{CHB}$ undergoing NUC therapy with a baseline HBsAg level of 2900-12,000 IU/mL was significantly higher than that in the other patients $(P=0.029$ and $P=0.338$, respectively) (Fig. 2b).

Role of plasma CLEC18 in the prediction of virological response in the patients with $\mathrm{CHB}$ receiving NUC treatment The overall NUC treatment duration was $61.68 \pm 2.30$ months for the HBeAg-negative patients. The times to virological response were $11.48 \pm 0.86$ months in the HBeAg-positive and $5.56 \pm 0.37$ months in the $\mathrm{HBeAg}$-negative patients with $\mathrm{CHB}$ receiving NUC therapy. In the HBeAg-positive patients, univariate analysis identified that a baseline HBsAg level of 2900$12,000 \mathrm{IU} / \mathrm{mL}$, HBV DNA level $<8.3 \log _{10} \mathrm{IU} / \mathrm{mL}$, ALT level $>5 \times$ ULN, and plasma CLEC18 level of 320-2000 pg/mL were significantly associated with virological response. Multivariate analysis identified that a baseline plasma CLEC18 level of 320-2000 pg/mL was an independent predictor of virological response
(HR: 1.850, 95\% CI: 1.109-3.085, $P=0.0184$ ) (Table 6). In the HBeAg-negative patients, no factor was significantly associated with virological response.

\section{Correlation between plasma CLEC18 and baseline HBsAg levels}

We analyzed the relationship between CLEC18 and HBsAg levels in the HBeAg-positive patients. CLEC18 and HBsAg levels had a low Spearman's correlation coefficient (data not shown). The correlation between categorized plasma CLEC18 levels (<320, 320-2000 and $>2000 \mathrm{pg} / \mathrm{mL})$ and categorized HBsAg levels $(<2900$, 2900-12,000 and >12,000 IU/mL) was not significant (see Additional File 2, $P=0.2558$ ).

\section{The association between plasma CLEC18 levels and liver fibrosis}

Of the 271 enrolled patients with $\mathrm{CHB}, 172$ received a liver biopsy. Univariate analysis identified that an age $>40$ years, female sex, HBV genotype $C$, baseline HBsAg < $3.0 \log _{10} \mathrm{IU} / \mathrm{mL}, \mathrm{HBV}$ DNA $<6 \log _{10} \mathrm{IU} / \mathrm{mL}$, ALT $<5 \times$ ULN, platelet $<150 \times 10^{3} /$ uL were significantly

Table 2 Plasma CLEC18 levels in the patients with CHB

\begin{tabular}{|c|c|c|c|c|}
\hline Group (viral load IU/mL) & Number of patients & CLEC18 level(Mean \pm SD pg/mL) & $P$ Value ${ }^{(1)}$ & $P$ Value ${ }^{(2)}$ \\
\hline Healthy donors & 35 & $3106.06 \pm 4708.13$ & - & - \\
\hline HBeAg-positive $\left(>2 \times 10^{7}\right)$ & 101 & $663.59 \pm 1375.62$ & $<0.001$ & - \\
\hline HBeAg-negative $\left(>2 \times 10^{7}\right)$ & 65 & $281.68 \pm 753.07$ & $<0.001$ & 0.0196 \\
\hline HBeAg-negative $\left(2000-2 \times 10^{7}\right)$ & 64 & $264.68 \pm 553.70$ & $<0.001$ & 0.0106 \\
\hline HBeAg-negative $(<2000)$ & 41 & 113. $28 \pm 231.69$ & $<0.001$ & 0.0057 \\
\hline
\end{tabular}

$P$ value $^{(1)}:$ Compared to healthy donors (Student's t-test)

$P$ value ${ }^{(2)}$ :Compared to $\mathrm{HBeAg}$-positive $\left(>2 \times 10^{7}\right)$ group (Student's t-test) 
Table 3 Factors associated with CLEC18 levels in the patients with CHB

\begin{tabular}{|c|c|c|c|c|c|c|c|c|}
\hline \multirow[t]{2}{*}{ Variables } & \multicolumn{4}{|l|}{ Univariate analysis } & \multicolumn{4}{|l|}{ Multivariate analysis } \\
\hline & Parameter Estimate & Standard Error & T Value & $P$ Value & Parameter Estimate & Standard Error & T Value & P Value \\
\hline Age & -18.41386 & 5.17495 & -3.56 & 0.0004 & -11.3821 & 6.1275 & -1.86 & 0.0644 \\
\hline Sex: Man vs Woman & -25.76591 & 128.98391 & -0.20 & 0.8418 & & & & \\
\hline Genotype: C vs B & 29.89732 & 126.53368 & 0.24 & 0.8134 & & & & \\
\hline HBeAg: (+) vs (-) & 428.94574 & 120.57574 & 3.56 & 0.0004 & 194.63847 & 162.600 & 1.20 & 0.2324 \\
\hline $\mathrm{HBsAg} \log _{10} \mathrm{IU} / \mathrm{mL}$ & 189.40927 & 67.77183 & 2.79 & 0.0056 & 20.737 & 91.28661 & 0.23 & 0.8205 \\
\hline HBV DNA $\log _{10} \mathrm{IU} / \mathrm{mL}$ & 85.07892 & 27.25278 & 3.12 & 0.0020 & 25.6009 & 40.78698 & 0.63 & 0.5308 \\
\hline Cirrhosis: Yes vs No & -142.57582 & 126.72962 & -1.13 & 0.2616 & & & & \\
\hline Fatty liver: Yes vs No & -38.09601 & 119.31101 & -0.32 & 0.7497 & & & & \\
\hline ALT: IU/L & 0.30495 & 0.14451 & 2.11 & 0.0358 & 0.09404 & 0.16072 & 0.59 & 0.5590 \\
\hline Total bilirubin: mg/dL & -5.61291 & 45.41720 & -0.12 & 0.9017 & & & & \\
\hline Platelet: $\times 10^{3} / \mu \mathrm{L}$ & 1.16809 & 0.97747 & 1.20 & 0.2331 & & & & \\
\hline PT: seconds prolonged & -19.80886 & 31.83170 & -0.62 & 0.5343 & & & & \\
\hline Cr: mg/dL & 17.03954 & 124.23906 & 0.14 & 0.8910 & & & & \\
\hline AFP: $n g / m L$ & 0.99144 & 0.79197 & 1.25 & 0.2117 & & & & \\
\hline $\begin{array}{l}\text { METAVIR Activity grade } \\
2,3 \text { vs } 0,1\end{array}$ & -102.09187 & 167.92687 & -0.61 & 0.5441 & & & & \\
\hline $\begin{array}{l}\text { METAVIR Fibrosis stage } \\
3,4 \text { vs } 0-2\end{array}$ & -303.34073 & 171.59770 & -1.77 & 0.0791 & & & & \\
\hline
\end{tabular}

associated with METAVIR fibrosis stages 3 and 4, while CLEC18 showed borderline significance $(P=0.0501)$. Multivariate analysis revealed that a baseline plasma CLEC18 level of $<320 \mathrm{pg} / \mathrm{mL}$ was not significantly associated with METAVIR fibrosis stages 3 and 4 (see Additional File 3).

\section{Discussion}

This is the first study to investigate the expression, association and predictive value of CLEC18 in HBV infection. Because it is difficult to obtain liver tissue in patients with $\mathrm{CHB}$, we analyzed the plasma levels of CLEC18 as an alternative.

Table 4 Factors associated with HBeAg loss in HBeAg-positive patients

\begin{tabular}{|c|c|c|c|c|}
\hline \multirow[t]{2}{*}{ Variables } & \multicolumn{2}{|l|}{ Univariate analysis } & \multicolumn{2}{|l|}{ Multivariate analysis } \\
\hline & Hazard Ratio $(95 \% \mathrm{Cl})$ & P Value & Hazard Ratio (95\% Cl) & P Value \\
\hline Age: $\geq 40$ vs $<40$ years old & $0.693(0.408-1.179)$ & 0.1761 & & \\
\hline Sex: Man vs Woman & $1.103(0.609-1.996)$ & 0.7466 & & \\
\hline Genotype: C vs B & $1.118(0.661-1.892)$ & 0.6774 & & \\
\hline Cirrhosis: Yes vs No & $1.150(0.617-2.144)$ & 0.6591 & & \\
\hline $\begin{array}{l}\text { HBsAg: } 2900-12,000 \mathrm{vs} \\
<2900 \text { or }>12,000 \mathrm{IU} / \mathrm{mL}\end{array}$ & $2.696(1.555-4.673)$ & 0.0004 & $2.108(1.133-3.924)$ & 0.0186 \\
\hline $\begin{array}{l}\text { HBV DNA: } \geq 8.3 \mathrm{vs} \\
<8.3 \log _{10} \mathrm{IU} / \mathrm{mL}\end{array}$ & $0.938(0.534-1.646)$ & 0.8223 & & \\
\hline $\mathrm{ALT}: \geq 5 \times \mathrm{Vs}<5 \times \mathrm{ULN}$ & $2.452(1.433-4.195)$ & 0.0011 & $2.055(1.145-3.690)$ & 0.0158 \\
\hline $\begin{array}{l}\text { Total bilirubin: } \geq 1.2 \text { vs } \\
<1.2 \mathrm{mg} / \mathrm{dL}\end{array}$ & $1.622(0.959-2.744)$ & 0.0713 & & \\
\hline PT: seconds prolonged & $1.130(0.995-1.282)$ & 0.0592 & $1.140(0.981-1.325)$ & 0.0865 \\
\hline Platelet: $\geq 150$ vs $<150 \times 10^{3} / \mu \mathrm{L}$ & $1.551(0.887-2.710)$ & 0.1234 & & \\
\hline AFP: $\geq 20 \mathrm{vs}<20 \mathrm{ng} / \mathrm{mL}$ & $3.178(1.732-5.829)$ & 0.0002 & $2.583(1.258-5.303)$ & 0.0097 \\
\hline CLEC18: pg/mL & $1.000(0.999-1.000)$ & 0.2708 & & \\
\hline $\begin{array}{l}\text { CLEC18: } 320-2000 \text { vs } \\
<320 \text { or }>2000 \mathrm{pg} / \mathrm{mL}\end{array}$ & $2.842(1.637-4.933)$ & 0.0002 & $2.077(1.066-4.046)$ & 0.0318 \\
\hline
\end{tabular}


Table 5 Factors associated with HBeAg seroconversion in the HBeAg-positive patients

\begin{tabular}{|c|c|c|c|c|}
\hline \multirow[t]{2}{*}{ Variables } & \multicolumn{2}{|l|}{ Univariate analysis } & \multicolumn{2}{|l|}{ Multivariate analysis } \\
\hline & Hazard Ratio (95\% Cl) & $P$ Value & Hazard Ratio $(95 \% \mathrm{Cl})$ & P Value \\
\hline Age: $\geq 40$ vs $<40$ years old & $0.700(0.363-1.351)$ & 0.2878 & & \\
\hline Sex: Man vs Woman & $0.741(0.370-1.485)$ & 0.3984 & & \\
\hline Genotype: C vs B & $1.480(0.756-2.898)$ & 0.2525 & & \\
\hline Cirrhosis: Yes vs No & $1.133(0.532-2.411)$ & 0.7464 & & \\
\hline $\begin{array}{l}\text { HBsAg: } 2900-12,000 \mathrm{vs} \\
<2900 \text { or }>12,000 \mathrm{IU} / \mathrm{mL}\end{array}$ & $1.754(0.897-3.340)$ & 0.1008 & & \\
\hline HBV DNA: $\geq 8.3$ vs $<8.3 \log _{10} \mathrm{IU} / \mathrm{mL}$ & $0.907(0.453-1.815)$ & 0.7832 & & \\
\hline $\mathrm{ALT}: \geq 5 \times \mathrm{Vs}<5 \times \mathrm{ULN}$ & $3.115(1.551-6.254)$ & 0.0014 & $2.562(1.241-5.288)$ & 0.0110 \\
\hline Total bilirubin: $\geq 1.2 \mathrm{vs}<1.2 \mathrm{mg} / \mathrm{dL}$ & $1.392(0.723-2.682)$ & 0.3228 & & \\
\hline PT: seconds prolonged & $1.114(0.955-1.298)$ & 0.1688 & & \\
\hline Platelet: $\geq 150$ vs $<150 \times 10^{3} / \mu \mathrm{L}$ & $1.149(0.565-2.336)$ & 0.7021 & & \\
\hline AFP: $\geq 20 \mathrm{vs}<20 \mathrm{ng} / \mathrm{mL}$ & $2.388(1.166-4.888)$ & 0.0173 & $1.950(0.927-4.103)$ & 0.0783 \\
\hline CLEC18: pg/mL & $1.000(0.999-1.000)$ & 0.3755 & & \\
\hline $\begin{array}{l}\text { CLEC18: } 320-2000 \text { vs } \\
<320 \text { or }>2000 \mathrm{pg} / \mathrm{mL}\end{array}$ & $2.609(1.342-5.072)$ & 0.0047 & $2.041(1.018-4.092)$ & 0.0445 \\
\hline
\end{tabular}

Plasma CLEC18 decreases during HBV infection. The natural history of chronic HBV infection includes four distinct phases: an immune-tolerant phase, an immune clearance phase, an inactive or residual phase, and a reactivation phase [19]. In the immune-tolerant phase, the patients tend to be younger and have higher HBV DNA levels. As the patients become older, the disease progresses to the inactive phase, and the patients experience $\mathrm{HBeAg}$ loss and seroconversion with a decrease in HBV DNA replicative activity $[22,23]$. We divided treatment-naïve patients with $\mathrm{CHB}$ undergoing NUC therapy into groups to mimic the disease progression of HBV infection. Interestingly, plasma CLEC18 levels were dramatically down-regulated in the patients with $\mathrm{CHB}$ (Table 2), suggesting that plasma CLEC18 levels are related to disease progression in HBV infection.

The baseline plasma CLEC18 levels were higher in the HBeAg-positive $\mathrm{CHB}$ patients than those in the HBeAg-negative $\mathrm{CHB}$ patients. Most of the HBeAg-negative CHB patients had low or even undetectable plasma CLEC18 levels, which precluded further evaluations of the associations with clinical features. The reason why the HBeAg-negative CHB patients exhibited low plasma CLEC18 levels is unknown, however it is possible that HBV infection down-regulates the expression of CLEC18 in the liver, and that long-term chronic infection with HBV results in lower plasma CLEC18 levels.

Previous studies have shown that HBV can attenuate the host immune response [10-12] such as by inhibiting TLR3-mediated cytokine response, which is correlated with the suppression of IFN- $\beta$ and suppressed activation of IRF-3 and NF-kB [24]. We speculate that CLEC18 may play a role in regulating PRR-mediated cytokine secretion or activating interferon-stimulating genes during viral infection. HBV blocks the expression of CLEC18, which may then result in attenuation of the host immune response. There were no significant correlations between baseline plasma CLEC18 and HBsAg levels, either in linear regression analysis or categorized correlation analysis. However, both may play a role in predicting HBeAg loss and/or seroconversion. The reason why we did not see a significant correlation between baseline plasma HBsAg and CLEC18 levels may be because most of the patients had low plasma CLEC18 levels, which precluded further statistical correlations with HBsAg levels in our study population. Further studies are needed to investigate whether plasma CLEC18 levels are correlated with HBsAg kinetics during NUC treatment. The mechanism by which HBV regulates the expression of CLEC18 during the disease course also remains to be elucidated.

Wang et al. reported that a high baseline HBsAg level $(>10,000 \mathrm{IU} / \mathrm{mL})$ was associated with a lower rate of virological response, and that an on-treatment decline in HBsAg alone was not a good predictor of HBeAg loss and seroconversion in patients with $\mathrm{CHB}$ undergoing entecavir treatment [25]. Similar studies have reported that baseline HBsAg level alone or in combination with on-treatment declines in $\mathrm{HBsAg}, \mathrm{HBeAg}$, and $\mathrm{HBV}$ DNA levels can increase the predictive accuracy of HBeAg seroconversion [26]. However, none of these studies identified a clear cutoff value of HBsAg to predict treatment outcomes in patients receiving NUC treatment. Interestingly, we demonstrated that the subgroups of patients with a baseline HBsAg level of 2900 $12,000 \mathrm{IU} / \mathrm{mL}$ had a higher likelihood of HBeAg loss 

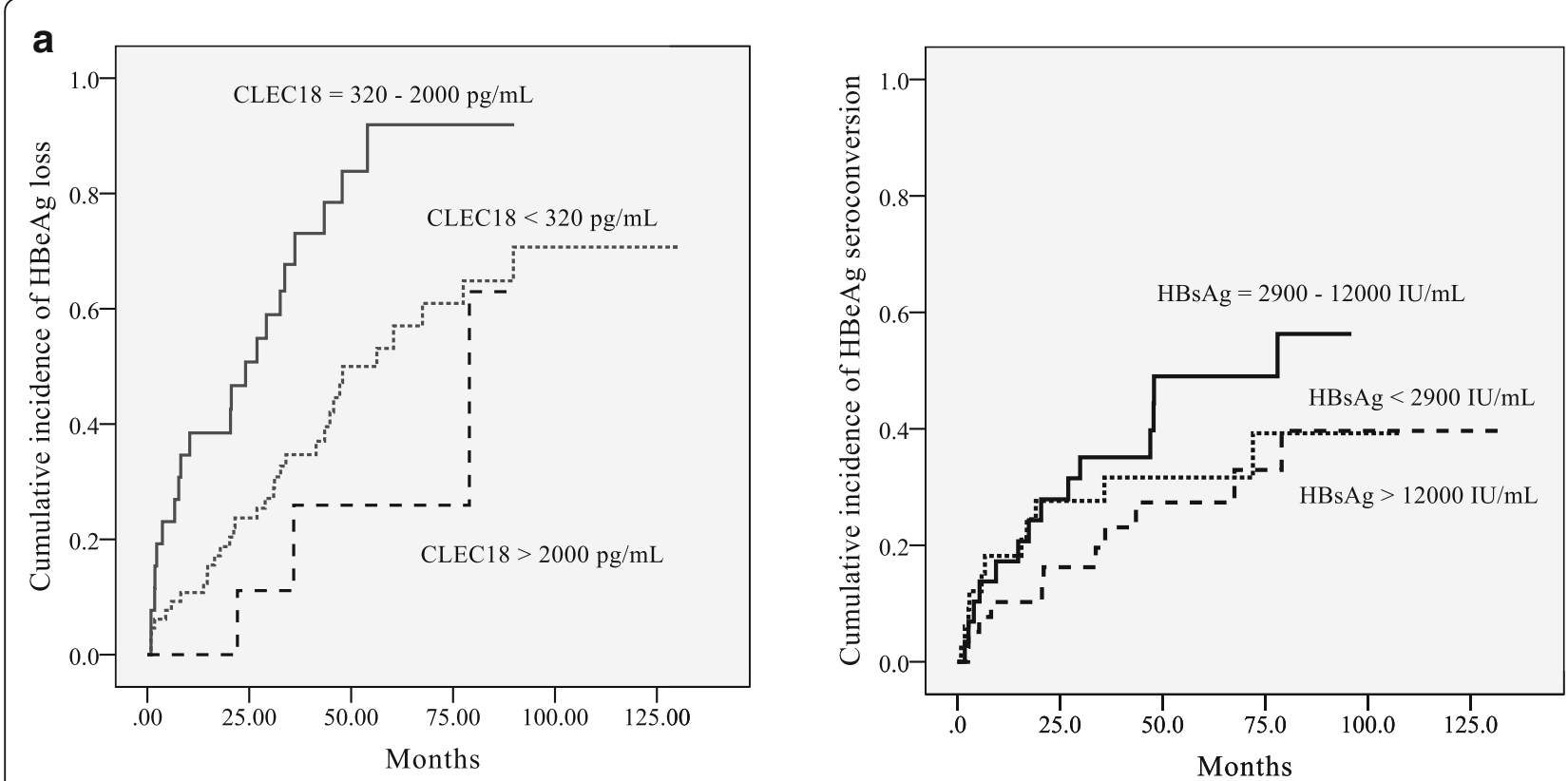

b
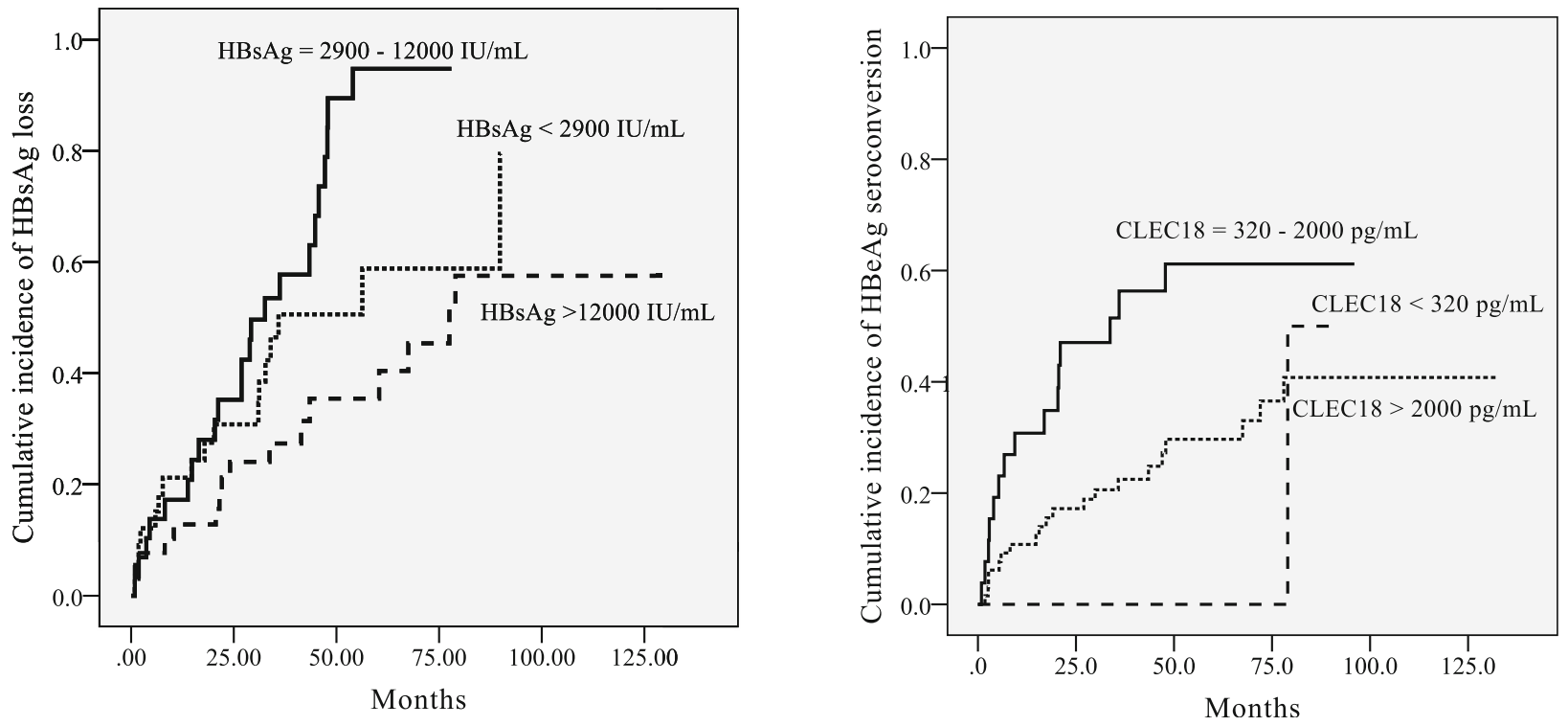

Fig. 2 Cumulative incidence of HBeAg loss and seroconversion in the patients with CHB by (a) CLEC18 and (b) HBsAg levels. Curves of cumulative rates of HBeAg loss and HBeAg seroconversion derived from Kaplan-Meier analysis stratified by (a) baseline plasma CLEC18 levels and (b) baseline $\mathrm{HBsAg}$ levels. Differences between cumulative incidence curves were tested using the log-rank test

and seroconversion. It is possible that the patients with $\mathrm{CHB}$ who had already achieved a low HBsAg level of $<2900 \mathrm{IU} / \mathrm{mL}$ and remained positive for HBeAg were less likely to lose $\mathrm{HBeAg}$ despite treatment, although the underlying immunological and virologic mechanisms remain to be determined. Patients with $\mathrm{CHB}$ with a high HBsAg level may have an impaired immune response to HBV owing to the inhibitory effect of viral antigens. The reason why the patients with a baseline $\mathrm{HBsAg}$ level of 2900-12,000 IU/mL and CLEC18 level of 320-2000 pg/
$\mathrm{mL}$ tended to achieve $\mathrm{HBeAg}$ loss remains unknown. We speculate that HBV regulates CLEC18 via an unknown pathway in $\mathrm{HBeAg}$-positive $\mathrm{CHB}$ patients receiving NUC therapy. This interaction between HBV and CLEC18 may then result in the apparent concordance in the associations between HBsAg and CLEC18 levels and HBeAg loss during NUC therapy. Further investigations into the underlying mechanism are needed. Although a baseline HBsAg level of 2900-12,000 IU/mL was significantly associated with HBeAg loss, it was not significantly associated 
Table 6 Factors associated with virological response in the HBeAg-positive patients

\begin{tabular}{|c|c|c|c|c|}
\hline \multirow[t]{2}{*}{ Variables } & \multicolumn{2}{|l|}{ Univariate analysis } & \multicolumn{2}{|l|}{ Multivariate analysis } \\
\hline & Hazard Ratio $(95 \% \mathrm{Cl})$ & $P$ Value & Hazard Ratio (95\% Cl) & P Value \\
\hline Age: $\geq 40$ vs $<40$ years old & $0.813(0.544-1.215)$ & 0.3125 & & \\
\hline Sex: Man vs Woman & $0.755(0.488-1.166)$ & 0.2045 & & \\
\hline Genotype: C vs B & $1.063(0.707-1.598)$ & 0.7691 & & \\
\hline Cirrhosis: Yes vs No & $1.257(0.778-2.031)$ & 0.3502 & & \\
\hline $\begin{array}{l}\text { HBsAg: } 2900-12,000 \mathrm{vs} \\
<2900 \text { or }>12,000 \mathrm{IU} / \mathrm{mL}\end{array}$ & $1.698(1.065-2.706)$ & 0.0260 & $1.449(0.890-2.359)$ & 0.1359 \\
\hline HBV DNA: $\geq 8.3$ vs $<8.3 \log _{10} \mathrm{IU} / \mathrm{mL}$ & $0.583(0.378-0.899)$ & 0.0147 & $0.395(0.247-0.631)$ & 0.0001 \\
\hline $\mathrm{ALT}: \geq 5 \times \mathrm{Vs}<5 \times \mathrm{ULN}$ & $1.909(1.240-2.939)$ & 0.0033 & $2.191(1.373-3.496)$ & 0.0010 \\
\hline Total bilirubin: $\geq 1.2 \mathrm{vs}<1.2 \mathrm{mg} / \mathrm{dL}$ & $1.301(0.861-1.967)$ & 0.2115 & & \\
\hline PT: seconds prolonged & $1.015(0.914-1.128)$ & 0.7751 & & \\
\hline Platelet: $\geq 150$ vs $<150 \times 10^{3} / \mu \mathrm{L}$ & $1.297(0.831-2.025)$ & 0.2525 & & \\
\hline AFP: $\geq 20 \mathrm{vs}<20 \mathrm{ng} / \mathrm{mL}$ & $1.230(0.742-2.038)$ & 0.4227 & & \\
\hline CLEC18: pg/mL & $1.000(1.000-1.000)$ & 0.9850 & & \\
\hline $\begin{array}{l}\text { CLEC18: } 320-2000 \text { vs } \\
<320 \text { or }>2000 \mathrm{pg} / \mathrm{mL}\end{array}$ & $1.979(1.238-3.163)$ & 0.0044 & $1.850(1.109-3.085)$ & 0.0184 \\
\hline
\end{tabular}

with a virological response in the $\mathrm{HBeAg}$-positive $\mathrm{CHB}$ patients receiving NUC therapy. The reason remains to be investigated.

Taken together, we propose that a range of baseline plasma HBsAg and CLEC18 levels is better than a single cutoff value to predict $\mathrm{HBeAg}$ loss and/or seroconversion in NUC-treated HBeAg-positive patients, and that a range of baseline plasma CLEC18 levels can predict a virological response in these patients.

Developing an accurate biomarker to allow for the early management of liver fibrosis is important. In the current study, a plasma CLEC18 level $<320 \mathrm{pg} / \mathrm{mL}$ was not significantly associated with liver fibrosis. Whether the level of CLEC18 in the liver reflects liver fibrosis is unknown. Although it was not possible to define liver fibrosis using CLEC18 as a single biomarker, whether CLEC18 can be used in combination with other biomarkers to predict liver fibrosis remains to be elucidated. Further studies are also needed to elucidate whether CLEC18 can be used as a biomarker for liver fibrosis.

There were two limitations to the present study. First, we focused on the prediction of treatment outcomes during NUC therapy, and patients who did not meet the criteria for receiving NUC therapy according to the APASL guidelines [2] were not enrolled, such as immune-tolerant patients (high HBV DNA > $2 \times 10^{7} \mathrm{IU} / \mathrm{mL}$, normal ALT levels, HBeAg-positive) and inactive $\mathrm{HBsAg}$ carriers (HBsAg-positive, anti-HBe-positive with persistent normal serum ALT levels and HBV DNA < $2000 \mathrm{IU} / \mathrm{mL}$ ). Further studies enrolling such subgroups of patients are warranted. Second, not all of the HBeAg-positive patients received the same treatment regimen. Nonetheless, the majority of the patients received potent NUCs, with 80 and 17 receiving entecavir and tenofovir, respectively, both of which are first-line therapy as recommended by the APASL guidelines [2].

\section{Conclusion}

Plasma CLEC18 levels were decreased in the patients with $\mathrm{CHB}$ and could predict $\mathrm{HBeAg}$ loss, seroconversion and virological response in the $\mathrm{HBeAg}$-positive patients with $\mathrm{CHB}$ undergoing NUC therapy. Further studies are warranted to clarify the role of CLEC18 in CHB.

\section{Additional files}

Additional file 1: Defined cutoffs of HBsAg and CLEC18 levels for HBeAg loss by CART. (TIF $2684 \mathrm{~kb}$ )

Additional file 2: Correlation between HBsAg and CLEC18 levels. (TIF 1367 kb)

Additional file 3: Factors associated with fibrosis stages 3 and 4 in the patients with CHB. (DOCX $22 \mathrm{~kb})$

\section{Abbreviations}

AFP: Alpha-fetoprotein; ALT: Alanine aminotransferase; APASL: Asian Pacific Association for the Study of the Liver; APRI: AST to platelet ratio index; AST: Aspartate aminotransferase; CART: Classification and regression tree; CDNA: Complementary DNA; CHB: Chronic hepatitis B; CLEC18: C-type lectin 18; ELISA: Enzyme-linked immunosorbent assay; FIB-4: Fibrosis-4; FRG: Fah -/-/Rag2-/-/IIrg-/-; HBeAg: Hepatitis B e antigen; HBsAg: Hepatitis B surface antigen; HBV: Hepatitis B virus infection; HR: Hazard ratio; NUC: Nucleos(t)ide analogue; PD-1: Programmed cell death protein-1; PRR: Pattern recognition receptor; PT: Prothrombin time; qPCR: Quantitative real time polymerase chain reaction; RNA: Ribonucleic acid; SD: Standard deviation; TLR: Toll-like receptor; TNF-a: Tumor necrosis factor-alpha; ULN: Upper limit of normal

\section{Acknowledgements}

We thank Dr. Ding-Shinn Chen for assistance with data analysis and interpretation. We thank Mi-Hua Tao for providing HBV-infected human liver FRG mice. We thank the Taiwan Mouse Clinic (NRPGM) for technical support 
in physiological metabolism experiments. We are also grateful to the technical services provided by the Transgenic Mouse Model Core Facility (NRPGM).

\section{Funding}

This work was supported by Academia Sinica and the Ministry of Science and Technology (MOST 106-2321-B-001-037, MOST 106-2320-B-001-023-MY3, MOST 105-2321-B-001-053, AS-105-TP-B08), and Summit and Thematic Research Projects.

\section{Availability of data and materials}

The datasets generated and/or analysed in the current study are not publicly available due to patient privacy, however they are available from the corresponding author on reasonable request.

\section{Authors' contributions}

TYT designed, performed, analyzed experiments, and wrote the manuscript. HIY data analysis and interpretation, YLH data analysis, MHT analyzed experiments, S-SY data analysis and interpretation, HCL data analysis. CYP and SLH designed, analyzed experiments, data interpretation, and drafted and revised the manuscript. All authors read and approved the final manuscript.

\section{Ethics approval and consent to participate}

This study was conducted in accordance with the Helsinki Declaration of 1975. All patients provided written informed consent before enrollment. The study was approved by the Research Ethics Committee of China Medical University Hospital, Taichung (CMUH106-REC2-006, CMUH106-REC2-092) and Research Ethics Committee of Academia Sinica, Taipei (AS-IRB02-106013), Taiwan.

\section{Consent for publication}

Not applicable.

\section{Competing interests}

The authors declare that they have no competing interests.

\section{Publisher's Note}

Springer Nature remains neutral with regard to jurisdictional claims in published maps and institutional affiliations.

\section{Author details}

'Ph.D. Program for Translational Medicine, China Medical University and Academia Sinica, Taichung and Taipei, Taiwan. ${ }^{2}$ Division of Hepatogastroenterology, Department of Internal Medicine, China Medical University Hospital, 2, Yude St., North District, Taichung 404, Taiwan. ${ }^{3}$ School of Medicine, China Medical University, Taichung, Taiwan. ${ }^{4}$ Genomics Research Center, Academia Sinica, 128, Academia Road, Sec. 2, Nankang District, Taipei 115, Taiwan. ${ }^{5}$ Institute of Biomedical Sciences, Academia Sinica, 128, Academia Road, Sec. 2, Nankang District, Taipei 115, Taiwan. ${ }^{6}$ Institute of Statistical Sciences, Academia Sinica, 128, Academia Road, Sec. 2, Nankang District, Taipei 115, Taiwan. ${ }^{7}$ Institute of Clinical Medicine, National Yang-Ming University, Taipei, Taiwan. ${ }^{8}$ Department of Medical Research, Taipei Veterans General Hospital, Taipei, Taiwan.

\section{Received: 14 February 2018 Accepted: 11 July 2018}

\section{Published online: 28 July 2018}

\section{References}

1. European Association For The Study Of The L. EASL clinical practice guidelines: management of chronic hepatitis B virus infection. J Hepatol. 2012;57:167-85.

2. Liaw YF, Kao JH, Piratvisuth T, Chan HL, Chien RN, Liu CJ, et al. Asian-Pacific consensus statement on the management of chronic hepatitis B: a 2012 update. Hepatol Int. 2012;6:531-61.

3. Lok AS, McMahon BJ. Chronic hepatitis B: update 2009. Hepatology. 2009;50: $661-2$.

4. Peng $\mathrm{CY}$, Hsieh TC, Hsieh TY, Tseng KC, Lin CL, Su TH, et al. HBV-DNA level at 6 months of entecavir treatment predicts HBeAg loss in HBeAg-positive chronic hepatitis B patients. J Formos Med Assoc. 2015;114:308-13.

5. Sterling RK, Lissen E, Clumeck N, Sola R, Correa MC, Montaner J, et al. Development of a simple noninvasive index to predict significant fibrosis in patients with HIV/HCV coinfection. Hepatology. 2006;43:1317-25.
6. Lin ZH, Xin YN, Dong QJ, Wang Q, Jiang XJ, Zhan SH, et al. Performance of the aspartate aminotransferase-to-platelet ratio index for the staging of hepatitis C-related fibrosis: an updated meta-analysis. Hepatology. 2011;53: $726-36$.

7. Enomoto M, Morikawa H, Tamori A, Kawada N. Noninvasive assessment of liver fibrosis in patients with chronic hepatitis B. World J Gastroenterol. 2014;20:12031-8.

8. Bonino F, Piratvisuth T, Brunetto MR, Liaw YF. Diagnostic markers of chronic hepatitis B infection and disease. Antivir Ther. 2010;15(3):35-44.

9. Zhang Z, Zhang JY, Wang LF, Wang FS. Immunopathogenesis and prognostic immune markers of chronic hepatitis B virus infection. J Gastroenterol Hepatol. 2012;27:223-30.

10. Huang YL, Pai FS, Tsou Y, Mon HC, Hsu TL, Wu CY, et al. Human CLEC18 gene cluster contains C-type lectins with differential glycan-binding specificity. J Biol Chem. 2015;290:21252-63.

11. Zoulim F, Luangsay S, Durantel D. Targeting innate immunity: a new step in the development of combination therapy for chronic hepatitis B. Gastroenterology. 2013;144:1342-4.

12. Chang J, Block TM, Guo JT. The innate immune response to hepatitis $B$ virus infection: implications for pathogenesis and therapy. Antivir Res. 2012;96: 405-13.

13. Jiang M, Broering R, Trippler M, Poggenpohl L, Fiedler M, Gerken G, et al. Toll-like receptor-mediated immune responses are attenuated in the presence of high levels of hepatitis B virus surface antigen. J Viral Hepat. 2014;21:860-72.

14. Shih YM, Sun CP, Chou HH, Wu TH, Chen CC, Wu PY, et al. Combinatorial RNA interference therapy prevents selection of pre-existing HBV variants in human liver chimeric mice. Sci Rep. 2015;5:15259.

15. Azuma H, Paulk N, Ranade A, Dorrell C, Al-Dhalimy M, Ellis E, et al. Robust expansion of human hepatocytes in fah-/-/Rag2-/-/IIrg-/- mice. Nat Biotechnol. 2007;25:903-10.

16. Bissig KD, Le TT, Woods NB, Verma IM. Repopulation of adult and neonatal mice with human hepatocytes: a chimeric animal model. Proc Natl Acad Sci U S A. 2007:104:20507-11.

17. Yang PL, Althage A, Chung J, Chisari FV. Hydrodynamic injection of viral DNA: a mouse model of acute hepatitis B virus infection. Proc Natl Acad Sci U S A. 2002;99:13825-30.

18. Peng $C Y$, Lai HC, Su WP, et al. Early hepatitis B surface antigen decline predicts treatment response to entecavir in patients with chronic hepatitis B. Sci Rep. 2017;7:42879.

19. Intraobserver and interobserver variations in liver biopsy interpretation in patients with chronic hepatitis C. The French METAVIR cooperative study group. Hepatology. 1994;20:15-20.

20. Wang CC, Tseng KC, Peng CY, Hsieh TY, Lin CL, Su TH. Viral load and alanine aminotransferase correlate with serologic response in chronic hepatitis B patients treated with entecavir. J Gastroenterol Hepatol. 2013;28:46-50.

21. Chou R, Wasson N. Blood tests to diagnose fibrosis or cirrhosis in patients with chronic hepatitis $C$ virus infection: a systematic review. Ann Intern Med. 2013;158:807-20.

22. Liaw YF, Chu CM. Hepatitis B virus infection. Lancet. 2009;373:582-92.

23. Hui CK, Leung N, Yuen ST, Zhang HY, Leung KW, Lu L, et al. Natural history and disease progression in Chinese chronic hepatitis B patients in immunetolerant phase. Hepatology. 2007;46:395-401.

24. Wu J, Meng Z, Jiang M, Pei R, Trippler M, Broering R, et al. Hepatitis B virus suppresses toll-like receptor-mediated innate immune responses in murine parenchymal and nonparenchymal liver cells. Hepatology. 2009:49:1132-40.

25. Wang CC, Tseng TC, Wang PC, Lin HH, Kao JH. Baseline hepatitis B surface antigen quantitation can predict virologic response in entecavir-treated chronic hepatitis B patients. J Formos Med Assoc. 2014;113:786-93.

26. Li MH, Zhang L, Qu XJ, Lu Y, Shen G, Li ZZ, et al. The predictive value of baseline HBsAg level and early response for HBsAg loss in patients with HBeAg-positive chronic hepatitis B during pegylated interferon alpha-2a treatment. Biomed Environ Sci. 2017;30:177-84. 